\title{
The Influence of Workplace Facilities on Lactating Working Mothers' Job Satisfaction and Organisational Commitment: A Case Study of Lactating Working Mothers in Accra, Ghana
}

\author{
Mrs. Abigail Opoku Mensah \\ Department Of Management Studies, School Of Business \\ University of Cape Coast, Ghana, West Africa
}

Tel: 233-244-629-069 E-mail: abigailpeasah3@yahoo.com

Received: January 5, 2011 Accepted: February 11, 2011 doi:10.5539/ijbm.v6n7p234

\begin{abstract}
The purpose of the study was to find out the influence of workplace facilities on lactating working mothers' job satisfaction and their commitment level at work. The subjects for the study were two hundred and sixty lactating working mothers who were working full time from five different organizations in the Accra Metropolis in Ghana with age range of 24-41 years, mean age of 32.2 and a standard deviation of 8.8 . Data were analyzed using descriptive statistics of mean, standard deviation and Analysis of Variance (ANOVA) was used at 0.05 levels of significance. The findings of the study revealed that, lactating working mothers who get Workplace Facilities are more committed to their work and also more satisfied with their work than those who do not get workplace facilities. This paper, therefore, suggests that employers should provide workplace facilities for lactating working mothers who want to continue the practice of exclusive breastfeeding when they return to work, Since the provision of workplace facilities benefit both the employers, the child and the working mothers. The result of this study is to help policy makers in Ghana to have a second look at the Ghana labour Act (2003) about employment of women especially lactating mothers who want to continue the practice of exclusive breastfeeding with full time work. The findings will also educate employers in Ghana about the benefit of workplace facilities for lactating working mothers and the organization as a whole.
\end{abstract}

Keywords: Workplace facilities, Lactating working mothers, Organizational commitment, Job satisfaction, Ghana

\section{Introduction}

To breastfeed or not to breastfeed when a lactating working mother returns to work is a dilemma many mothers face after just having had their baby. The dilemma every mother faces at this time is not so much about what to feed her baby, but the whole issue surrounding the concept of leaving her baby and returning to work in an organization where there are no workplace facilities to support them continue the practice of exclusive breastfeeding with full- time work.

Many mothers return to work shortly after giving birth and they have to leave their babies at home. They are not able to breastfeed their babies properly as required by the World Health Organization (W.H.O, 2000) because of lack of workplace facilities in most organizations. It is recommended by W.H.O (2000) that, infants should be fed exclusively with breast milk from birth to six months of age. The question is how can working mothers be able to combine full time work with the practice of exclusive breastfeeding when there are no workplace facilities for them in their working environment.

According to Wallis (2004), the number of mothers who do not get support at the workplace and are breastfeeding their babies and working at the same time in the United States, has decreased over some time now. This is very common among professional women who have young children. However, breastfeeding is acknowledged as the best nutrition for young babies, it therefore needs to be protected, supported and promoted. This includes enabling mothers to continue breastfeeding even when they return to work.

According to the Ghana Labour Act (2003), on employment of women, a working mother is entitled to disrupt her work for an hour during her working hours to nurse her baby. The question here is, would it be possible in Ghana for lactating working mothers to go home during working hours time and breastfeed her baby within that one hour break given to them?, can she even get to her house on time to breastfeed and come back to work since there is always traffic in most places in Accra? It becomes very difficult for mothers who want to practice exclusive breastfeeding to feed their babies directly from the breast when there are no or not enough workplace facilities to support them. In 1919, when the International Labour Organization (ILO) was founded, maternity protection was the subject of its third Convention. At first the focus was on protection for the health of the baby and mother. 
Lactation breaks were part of the package for working mothers. Lactation breaks, which include both feeding the baby directly, make it possible for lactating women to function in the workplace and maintain their ability to breastfeed without having any difficulties.

In Ghana most lactating working mothers' do not have these facilities at their workplaces to be able to combine the practice of exclusive breastfeeding with full-time work properly and hence may affect their functions at work. Women's' participation in the labour force is on the increase as a result of increased women education, training, urbanization and the demands of the present day economy in Ghana. However, there is no or little support for lactating working mothers in Ghana.

According to Rextroat, (1992); Usman (2005); and Clark, ( 2006) Job satisfaction is the effective orientation of individuals towards work roles that they are currently occupying. One could be said to be satisfied with one's job to the extent that the job fulfils one's dominant needs and values. It can be concluded that, when lactating working mothers get satisfied with their jobs as a result of the presence of workplace facilities to help them combine work with the practice of exclusive breastfeeding, they are more likely to be satisfied and also get committed to their jobs.

More than half of American mothers of children under the age of three years participate in the workforce. The return to work postpartum often coincides with cessation of breastfeeding, suggesting that women employed outside the home face workplace-related challenges to continue lactation, again this situation is not different in Ghana. It follows that workplace accommodations for lactating mothers are important to achieve United States Healthy People 2010 objectives of $50 \%$ of mothers to breastfeed for 6 months and $25 \%$ breastfeeding for 1 year. This study sought to find out whether the presence or the absence of workplace facilities will have any influence on Lactating working mothers job satisfaction and hence their commitment level in paid employment in Ghana.

\subsection{Definition of Terms}

- Exclusive Breastfeeding: The proportion of infants less than six months of age who received only breast milk. (Labbok and Krasovec, 1990)

- Workplace Facilities: They are facilities provided by the employer to help lactating working mothers combine work with breastfeeding effectively and they include: Lactation breaks, flexible work options and equipments.

\subsection{Significance of the study}

The findings from the study might supply information to address some of these issues:

- The information from this study might create awareness for policy makers in Ghana to come out with sound policies for employers to ensure the provision of workplace facilities for lactating working mothers such as flexible work options etc.

- The findings might also sensitize employers in Ghana to provide workplace facilities such as private rooms for lactating working mothers to ensure successful breastfeeding. This might in turn contribute to their job satisfaction and their commitment level at work.

- Releasing the results of this report might encourage employers to provide good working conditions such as lactation breaks to enable lactating working mothers combine work with exclusive breastfeeding effectively.

- The results from the study might also provide insights into the benefit of workplace facilities for lactating mothers who are about to resume work after their maternity leave.

\section{Literature Review}

Recent statistics show that more than half of breastfeeding mothers are in the labour market. (Thompson \& Bell, 1997). Nationwide statistics also revealed that women face barriers in their attempt to combine full time work with the practice of exclusive breastfeeding when they resume work (Blum, 1993; Thompson \& Bell, 1997).

According to Judith Galtry (2000), three main workplace facilities are required for women to successfully combine work with breastfeeding.

- First, lactation break: to enable the mother to either express breast milk or go to feed her baby during working hours. The International Labour Organization (1997) recommends one or more daily breaks or a daily reduction of hours of work which is counted as working time and remunerated accordingly. The facility of adding these breaks to their lunch break would allow the mothers to travel to breastfeed their babies.

- Second, workplace facilities: A clean, hygienic and private area in which women could express breast milk or breastfeed their babies if the baby was brought to the workplace;

- Thirdly, a flexible work options: Enable breastfeeding mothers to work at a more flexible hour in the early weeks and months following childbirth. 
Two out of three mothers work outside the home (Suarez, 1998). According to a Bureau of National Affairs Special Report, the fastest growing segment of the labour market today is composed of mothers with infants and toddlers Cohen \& Mrtek (1994). They also reported that more than half of women with children under one year of age are in the Labour market and this situation is not different in Ghana. This is further supported by Lindberg (1996), who concluded in his study that at least $50 \%$ of women who are employed when they become pregnant return to the Labour force by the time their children are three months old. This is clear evidence that mothers who have children aged three months or less or mothers who are lactating return to work after their short maternity leave in Ghana. It is therefore very important to pay attention to such working mothers at the workplace since their number keeps on increasing (Lindberg, 1996).

Mothers facing workplace obstacles to breastfeeding at the workplace are more likely to experience some psychological problems such as tension and anxiety. When mothers encounter barriers to breastfeeding upon their return to work, they may also feel guilty about being unable to successfully meet the demands of being a mother and to play their employee roles. For many mothers, this is when breastfeeding ends for most women. The stress associated with the role conflict may affect the quality of a woman's work. (Gates \& O'Neill, 1990).

Mothers who are not able to breastfeed or reduce their duration of breastfeeding their babies because of the absence of workplace facilities extend their stress to the workplace which affect their employers and their work outcomes. According to Cohen et al, (1995) there was higher rates of employee absenteeism and lost income was associated with incidences of illnesses among infants who are not breastfed. In fact, they did a comparison study of maternal absenteeism and infant illness rates; they found that of the 40 illnesses causing 1 day's absence for employed mothers, only $25 \%$ occurred in breastfed babies while $75 \%$ occurred in formula-fed babies.

A study was conducted in February 2007, descriptive statistics and linear regression was used to assess attitudes towards workplace breastfeeding/milk expression among employees $(n=407)$ of a large U.S. corporation providing a wide variety of workplace accommodations for lactating mothers. The result obtained was that, overall, attitudes about the impact of breastfeeding on the work environment were favorable. Previous exposure to a co-worker who breastfed or expressed milk during the work day was associated with a positive attitude towards workplace breastfeeding, even after controlling for respondents' gender, length of employment and personal breastfeeding history. The researcher concluded that lactation accommodations did not have negative repercussions for other employees, and that a corporate environment designed to enable and encourage continued breastfeeding does not endanger positive attitudes towards breastfeeding in other employees. Suyes K, A brahams SW, Labbok MH (2008). One could infer from this that having; the absence or the presence of workplace facilities can have some association with lactating working mothers' commitment level at the workplace.

Dodgson (2001) conducted a cross-sectional survey which was completed by nurse managers or lactation consultants most knowledgeable about supports to breastfeeding employees in 19 hospitals. He found out that the number of mothers with workplace breastfeeding supports or breastfeeding Support Score $(\mathrm{M}=7.47$; sd = 3.37) varied considerably. Which means that, breastfeeding support score for government-funded hospitals was significantly higher $(\mathrm{t}=2.31 ; \mathrm{P}=0.03)$ than for private hospitals. Of the 14 hospitals that had a designated space for using a breast pump, only five $(26.3 \%)$ had a private room with a door that locked. Only two hospitals (11.1\%) allowed employees to take breaks as needed to use a pump; employees in $10(55.6 \%)$ had to use their meal and regular break times. Hospitals having a hospital-wide committee that addressed workplace breastfeeding issues had a more supportive environment for breastfeeding employee. He concluded in his research that, employers who facilitated the continuation of breastfeeding after employees (lactating mothers) returned to work were those employers who understood the needs of breastfeeding employees. So therefore one can infer that, the absence or the presence of workplace facilities does affect the mothers' feelings and their work output.

A study by Yimyam, Marrow and Srisuphan, (1999), combined both qualitative and quantitative methods in Thailand with a sample of 313 employed women who did not have lactation breaks in their respective organization to help them combine the practice of exclusive breastfeeding with full time work. The result of their study revealed that, $94 \%$ of the mothers' breastfed for at least one month. Those who resumed employment; $26 \%$ stopped breastfeeding before or at the time of resumption, while $74 \%$ continued breastfeeding. Within the space of one month after the return to work another $24 \%$ totally weaned their infants and only 114 mother's continued breastfeeding for varying periods. This study concluded that employed Chiang Mai women were committed to breastfeeding but resumption to employment presented difficulties particularly when their employment was characterized by rigid working hours and long separation from infants. This conclusion from Yimyam et al. (1999) identified certain obstacles at the workplace that can prevent mothers from breastfeeding example are rigid working hours and separation from infant.

According to Robinson Hood (1998), Breastfeeding at the workplace can offer a considerable return on investment for employers by lowering health cost, reducing absenteeism, enhancing productivity, increasing retention, improving corporate image, reduces staff turnover and loss of skilled workers after the birth of a child. Specifically, implementation of workplace facilities such as Lactation breaks, Flexible work option and the provision of certain facilities at the workplace would help the mothers combine full time work with the practice of exclusive breastfeeding. 
Weiss (2002) has argued that job satisfaction is an attitude but points out that researchers should clearly distinguish the objects of cognitive evaluation which affect emotion, beliefs and behaviours. That is to say that we form our attitude towards our jobs by taking into account our feelings, our beliefs and our behaviours. One could be said to be satisfied with one's job to the extent that the job fulfils one's dominant needs and values (Rextroat, 1992; Usman 2005; and Clark, 2006).

Although World Health Organization (2000) recommends exclusive breastfeeding for babies, it is quite impossible for mothers who are working full time in Ghana to combine work with the practice of exclusive breastfeeding. Based on the above premises, the following hypotheses were generated:

H1: lactating working mothers who get lactation breaks will be more satisfied with their jobs than those who do not get lactation breaks in their respective organization.

$\mathrm{H} 2$ : lactating working mothers who get lactation breaks will be more committed to their jobs than those who do not get lactation breaks in their respective organization.

H3: Lactating working mothers who get flexible work options will be more satisfied with their work than those who do not get flexible work option.

H4: Lactating working mothers who get flexible work options will be more committed to their work than those who do not get flexible work option.

H5: Lactating working mothers who get facilities such as private rooms, comfortable seats etc to breastfeed their babies will be more satisfied with their jobs than those who lack these facilities.

H6: Lactating working mothers who get facilities such as private rooms, comfortable seats etc to breastfeed their babies will be more committed to their jobs than those who lack these facilities.

\subsection{Theoretical Framework}

The study is based on the Affect theory by Locke (1976) and the Affective commitment theory by Meyer and Allen (1990). The main premise of Locke's theory is that job satisfaction is determined by the discrepancy between what one wants in a job and what one has on the job. In practice, lactating working mothers who want workplace facilities to be able to combine full time work with exclusive breasting will be satisfied and committed to their jobs especially when they lack these facilities in their respective organizations.

The second theory looked at organizational commitment which in general terms can be defined as an employee's psychological attachment to the organization. For the purpose of this study, Meyer \& Allen's model of commitment was used. According to Meyer and Allen's (1990), there are three-component model of commitment which indicates that, there are three "mind sets" which can characterize an employee's commitment to the organization and they are: Affective Commitment, Continuance Commitment and Normative Commitment. For the purpose of this study, Affective commitment level of the lactating working mothers' was measured. Affective commitment is about an employee's positive emotional attachment to the organization. The main premise of this theory of commitment is that, lactating working mothers' who are affectively committed to their work because of the presence of workplace facilities at the workplace to assist them combine exclusive breastfeeding with full time work will strongly identify themselves with the goals of the organization and desires to remain a part of the organization.

\section{Data and Methodology}

The sample of the study was made up of two hundred and sixty (260) lactating working mothers who were full time workers and aged ranged 24-41 years and were selected from five different organizations in the Accra Metropolis, Ghana. The institutions selected were the Hospitals, Schools, Banks, Non-Governmental Organizations (N.G.O) and the Ministries. The reason for selecting these Organizations was that, they were among the very few Organizations that one could find a lot of female employees here in Ghana. Data were collected under standardized condition and procedures.

\subsection{Study Area}

Accra metropolis is located in the greater Accra region in Ghana. It is the most populated region in Ghana. Five different kinds of organizations were purposely chosen for this study. The organizations selected were the hospitals, schools, ministries, non- governmental organizations and the Banks. These organizations were among the very few firms that one could find a lot of female employees in Ghana.

\subsection{Study Design}

This study was a survey of job satisfaction and job commitment of lactating working mothers' in their jobs. Mothers who were then breastfeeding and were working full time were selected for the study. Mothers with multiple babies were excluded in this study as they were more likely to have difficulties in practicing exclusive breastfeeding with full time work.

Purposive sampling technique was used to select the participants because the researcher had in mind a targeted group of mothers, that was mothers who were breastfeeding and working full time the at the time of the study . All mothers who were currently breastfeeding in the selected organizations for the study were used. A total of 300 
questionnaires was distributed and to lactating working mothers and 260 questionnaires was retrieved back and was completely filled. Ethical approval for the study was obtained from the management of the selected organizations for the study. The participants were also briefed about the purpose of the study and their consent was sought.

\subsection{Questionnaire}

A questionnaire with closed ended questions was used and was distributed to participants. The questionnaire was composed of the following variables; Demographic factors of the mothers, job satisfaction scale and commitment scale was used to test the mothers' satisfaction and commitment levels.

Brayfield and Rothe (1951) Job Satisfaction scale was used to test the satisfaction levels of the mothers. Meyer and Allen (1990) Scale was used to test the commitment levels of the mothers in this study. The questionnaire was pre-tested using a sample of 50 lactating working mothers. These mothers were selected outside the original study area. Pre-testing of the scales helped the researcher to test the reliability and the suitability of the scales since they were adopted from a different culture. Few open - ended questions were added to the original scale and the information gathered from them was used in the discussion. Reliability co-efficient alpha of 0.92 was obtained for Job Satisfaction scale and reliability co-efficient alpha of 0.87 was obtained for the Organizational commitment scale. This means that the scales were highly reliable.

\subsection{Subject Collection Criteria}

Work status of the mothers was controlled, making sure that all the mothers who participated in the study was mothers who were working full time and were also breastfeeding their babies.

A permission letter was first of all given to the management to enable the researcher have access to the working mothers since the researcher visited the various organizations during working hours time. All the participants were briefed about the purpose of the study and their consent was sought. After briefing them about the main purpose of the study, questionnaires were given to them to be completed. Different dates were given to the researcher to collect the completed questionnaires.

\section{Results and Data Analysis}

Data collected were analyzed using Descriptive Statistics of Mean, Standard Deviation and Analysis of Variance (ANOVA). The alpha was set at 0.05 level of significance. Analysis of Variance (ANOVA) was used to test the differences between means of the interval data variables. The Hypotheses were tested on significant $(\mathrm{P} \leq 0.05)$

\section{$=$ INSERT TABLE 1 HERE $=$ \\ $=$ INSERT TABLE 2 HERE $=$}

The table revealed that some of the hypotheses were significant and others were not significant. Hypothesis One (H1:) was to find out whether lactating working mothers who get lactation breaks would be satisfied with their jobs than those who do not get lactation breaks in their respective organization. and Hypothesis Two (H2:) was to find out whether lactating working mothers who get lactation breaks would be committed to their jobs than those who do not get lactation breaks in their respective organization. The result revealed that, lactating working mothers who had lactation breaks in their respective organizations were more satisfied than those who did not have lactation breaks. The associated significant value was less than 0.05 . But there was no significant difference between lactating working mothers who had lactation breaks and their commitment level. They scored less on the commitment scale. This means that, despite the presence or the absent of lactation breaks for them, it did not contribute to them being committed or not to their organizations. The associated significant value was more than 0.05 .

The third and the fourth hypotheses were tested. The third hypothesis (H3:) stated that lactating working mothers who get flexible work options will be more satisfied with their work than those who do not get flexible work option. The fourth hypothesis (H4 :) stated that lactating working mothers who get flexible work options will be committed to their work than those who do not get flexible work option. The significant value for hypothesis three was less than 0.05. This made it significant and supports the study conducted by Yimyam et al. (1999). Mothers who work on flexible time basis were more satisfied with their jobs than those who did not have flexible work options. However, Lactating working mothers who had flexible work option were not committed to their jobs. The significant value (1.000) was more than 0.05 .

The fifth hypothesis (H5:) was tested and the hypotheses stated that, lactating working mothers who get facilities such as private rooms, comfortable seats etc to breastfeed their babies at the workplace will be satisfied with their jobs than those who lack these facilities. Hypothesis six (H6:) which stated that lactating working mothers who get facilities such as private rooms, comfortable seats etc to breastfeed their babies will be committed to their jobs than those who lack these facilities.

These very hypotheses were supported. The significant value for hypothesis five (H5) was .000 and hypothesis six (H6) was .0000 which are less than 0.05 . This means that, lactating working mothers who had such facilities in their respective organizations were more satisfied and committed to their jobs. The result supported the study by Robinson Hood (1998) which indicated that lactating working mothers who get workplace facilities have so many 
potential benefits as well as the organization itself. Dodgson (2001) also concluded in his study that, the provision of private rooms for lactating mothers to express breast milk or to breastfeed their babies at the workplace does affect them psychologically. It can therefore be inferred that the provision of these facilities does affect the feelings of these mothers hence their commitment to their job and also their output. One cannot underestimate the fact that the presence of workplace facilities in organizations has influence on lactating mothers' job satisfaction level and their commitment level.

\section{Discussion}

Hypothesis 1(H1): was supported which means that: lactating working mothers who get lactation breaks were more satisfied with their jobs than those who do not get lactation breaks in their respective organization. This particular result was in consonance with Shalowitz, (1993). He concluded in his study that, lactating working mothers' who get their usual breaks in addition to breaks specifically assigned for them to breastfeed their babies during working hours are more satisfied with their jobs than those who do not get lactation breaks. In fact a study conducted by Suyes et al. (2008) revealed that, breastfeeding at the workplace or expressing breast milk at the work place did not have any negative effect on other employees. One can concluded that when employers give lactating working mothers the chance to breastfeed during their lactation breaks at the workplace it will not have any negative effect on the mothers. This can however contribute to the mother's satisfaction level.

Hypothesis 2(H2): was not supported, which means that : lactating working mothers who get lactation breaks were not committed to their jobs than those who do not get lactation breaks in their respective organization. This particular hypothesis was not in consonance with Shalowitz, (1993) who concluded in his study that, lactating working mothers who get lactation breaks in addition to their usual breaks involved themselves more at work than those who do not get lactation breaks. Mothers' who are said to be committed with their work are more likely to be involved with their work. This difference in results may be due to other variables that the researcher did not look at which in one way or the other can contribute to the mothers' commitment level to work. Again, the difference in the result can be due to the difference in culture under which the research was conducted or the attitude of Ghanaian women to work could be so different from other countries.

Hypothesis 3(H3): was supported, which means that: lactating working mothers who get flexible work options were satisfied with their work than those who do not get flexible work option and Hypothesis 4(H4): which stated that lactating working mothers who get flexible work options will be more committed to their work than those who do not get flexible work option was significant. These results supported that of Yimyam et al. (1999) study. Their study concluded that employed Chiang Mai women were committed to breastfeeding but resumption to employment presented difficulties particularly when their employment was characterized by rigid working hours and long separation from infants. This conclusion from Yimyam et al. (1999) identified certain obstacles at the workplace that can prevent mothers from breastfeeding example are rigid working hours and separation from infant. When lactating working mothers' work under such conditions they are more likely not to be satisfied with their work and also not able to get committed to their jobs. Flexible work option is a very essential condition that lactation working mothers' who want to continue the practice of exclusive breastfeeding with full time work should have. In Ghana, the availability of flexible work options for some of the working mothers in some organizations made it possible for them to combine the practice of exclusive breastfeeding with full time work.

Hypothesis 5(H5): was supported which means that: lactating working mothers who get facilities such as private rooms, comfortable seats etc to breastfeed their babies were satisfied with their jobs than those who lack these facilities. Hypothesis 6(H6): was also significant which means that: lactating working mothers who get facilities such as private rooms, comfortable seats etc to breastfeed their babies were committed to their jobs than those who lack these facilities. These two results were in support of Cohen et al. (1995) results. Cohen et al. (1995), in their study compared maternal absenteeism and lack of workplace facilities, they concluded that mothers who were breastfeeding and did not get certain facilities to help them continue the practice of exclusive breastfeeding with full time work absented themselves more from work than those who were not breastfeeding. In a day, maternal absences were 3 times more common among mothers breastfeeding and did not get any support at work. It is very clear from the result that the presence of certain facilities such as private rooms for breastfeeding contributes greatly to lactating working mothers' job satisfaction level and their commitment level.

\section{Conclusion}

It could be concluded from the result in this study that, the presence of workplace facilities has so many potential benefits for lactating working mothers as well as the organizations in which they work with. Lactating working mothers' who are satisfied with their jobs and also committed to their jobs are more likely to contribute greatly to the growth of their organizations and also involved with the activities of the organization. However, most organizations in Ghana do not make these facilities available for the lactating mothers who want to continue the practice of exclusive breastfeeding when they resume work. The result of this study can help lactating working mothers to negotiate with their employers to provide workplace facilities for them before they resume work since that will make them more satisfied and committed to their work and also contribute greatly to the growth of the organization. 
It is recommended that employers in Ghana should make workplace facilities available for the lactating working mothers who want to continue the practice of exclusive breastfeeding when they resume work since it influences the mothers' job satisfaction level and their commitment level to work

According to Edd (2004), lactating working mothers face a lot of challenges when they do not get workplace support. Employers can reduce many workplace challenges with a small investment of time, flexibility and money. "Supervisors or employers are advised to provide opportunities for mothers to be more successful with breastfeeding during the workday. This includes being supportive and making necessary accommodations for workplace facilities for lactating mothers. The result of the study clearly indicates that, when employers support lactating working mothers, it contributes to their satisfaction level and commitment level. This implies that management in organizations should make a conscious effort to support these mothers. In addition, organizations where there are support, management should be able to educate pregnant women about the available support they can get when they return to work after their maternity leave. However, in organizations where there is no support for this group of mothers, their satisfaction level and commitment level will go down. When this happens it can go a long way to affect the total output of the individual and the organizations image.

\subsection{Recommendations}

Lastly, these are some recommendations made at the end of the study.

- It is recommended that further research could be carried out to find out if there are different variables that make lactating working mothers more satisfied and committed to their jobs.

- It is also recommended that future researchers should identify more organizations in Ghana which provide workplace facilities for lactating working mothers and come out with more potential benefits that organizations may get, when they provide workplace facilities for lactating working mothers.

- Further work should be done to assist organizations to develop and implement policies and procedures to help balance breastfeeding and work, so that breastfeeding mothers who are returning to work can continue to breastfeed as long as they and their baby require it.

- It was observed at the end of the study that, lactating working mothers needed more than the lactation breaks, flexible work options and equipment. Some of the mothers indicated the importance of having the support from colleagues at the workplace which this study did not take into consideration. It is therefore recommended that future studies should be done to find out how the absence or the presence of colleagues support at the workplace do affect lactating working mothers job satisfaction and their commitment level.

- Lastly, it is recommended that employers should ensure the provision of workplace facilities for lactating working mothers since they increase the mothers' job satisfaction and commitment level at the work place.

\section{Acknowledgments}

I give thanks to the Almighty God for seeing me through this research. I also appreciate the support from my husband (Eric), daughter (Michelle) and son (Michael)

\section{References}

Allen, N. J., \& Meyer, J. P. (1990). The measurement and antecedent of affective, continuance and normative commitment to the organization. Journal of Applied Psychology, 35, 1-18.

Blum, L. (1993). Mothers, babies, and breastfeeding in late capitalist America: The shifting contexts of feminist theory. Feminist Studies, 19, 291-311.

Brayfield, A. H., \& Rothe. H. F. (1951). An index of job satisfaction. Journal of Applied Psychology, 35, 307-311. Cohen, R., \& Mrtek, M. (1994). The impact of two corporate lactation programs on the incidence and duration of breastfeeding by employed mothers. [Online] Available: http://www.heapro.oxfordjournals.org/content/17/3/215.full

Cohen, R., Mrtek, M., \& Mrtek,R. (1995). Comparison of maternal absenteeism and infant illness rates among breast-feeding and formula-feeding women in two corporations. American Journal of Health Promotion, 10, 148-153.

Dodgson, J.E., Chee, Y.O., \& Yap, T.S. (2004). Workplace breastfeeding support for hospital employees. Journal of Advanced Nursing, 47(1), 91-100

Galtry, J. (2000). Gender and Society. Sage Publications, Inc. 142, 295-317.

Gates, D. M., \& O’Neill, N. J. (1990). Promoting maternal-child wellness in the workplace. AAOHN Journal, 38(6), 258-263.

Labbok M \& Krasovec, K. (1999). Toward consistency in breastfeeding definitions. Student Family Planning, 21(4), 226-30.

Labour Act. (2003). Part VI Employment of Women. Act 651. Accra: Assembly Press. 
Lindberg, L.D. (1996). Women's decisions about breastfeeding and maternal employment. Journal of Marriage and the Family, 58, 239-251.

Locke, E. A. (1976). The Nature and Causes of Job Satisfaction. In M.D. Dunnette (Eds), Handbook of Industrial and organizational psychology. (1297-1349) Chicago IL: Randy. McNally.

Shalowitz, D. (1993). Lactation program speeds mothers' return to work. Business Insurance, 27(40), 21.

Suarez, R. (1998). Breastfeeding. In Talk of the Nation. Washington, D.C.

Suyes, K, Abrahams, S.W., \& Labbok, M.H. (2008). Breastfeeding in the workplace: Other employees' attitudes towards services for lactating mothers. International Breastfeed Journal, 20(3), 25

Thompson, P., \& Bell, P. (1997). Breastfeeding in the workplace: How to succeed. Issues in Comprehensive Pediatric Nursing, 20, 1-9.

Wallis, C. (2004). The case for staying home. Time, 51-59.

World Health Organization. (2000). Effects of breastfeeding on infants and child mortality due to infectious diseases in less developed countries: a pooled analysis. Lancet, 355: 451-455.

Yimyam, S., Morrow, M., \& Srisuphan, W. (1999). Role of conflict and rapid socio-economic change: Breastfeeding among employed women in Thailand. Science and Medicine, 49, 957-965.

Table 1. Demographic data of participants

\begin{tabular}{|l|l|l|l|l|}
\hline $\begin{array}{l}\text { Demographic } \\
\text { characteristics }\end{array}$ & Minimum & Maximum & Mean & $\begin{array}{l}\text { Standard } \\
\text { Deviation }\end{array}$ \\
\hline Age of Mothers & 24 & 41 & 32.2 & 8.8 \\
\hline $\begin{array}{l}\text { Number of } \\
\text { children }\end{array}$ & 1 & 6 & 2.2 & 1.2 \\
\hline $\begin{array}{l}\text { Age of last born } \\
\text { of Children }\end{array}$ & 3 months & 12 months & $8.7 \mathrm{~m}$ & 8.2 \\
\hline
\end{tabular}

Table 2. Summary of chi square results of the test of hypotheses

\begin{tabular}{|l|l|l|l|}
\hline Hypothesis & F- Value & DF & $\begin{array}{l}\text { Asymp: Sig. } \\
(2-S i d e d)\end{array}$ \\
\hline Hypothesis 1 & .005 & 1 & .001 \\
\hline Hypothesis 2 & .046 & 1 & 1.000 \\
\hline Hypothesis 3 & 14.935 & 1 & .000 \\
\hline Hypothesis 4 & 8.60 & 1 & 1.000 \\
\hline Hypothesis 5 & 20.056 & 1 & .000 \\
\hline Hypothesis 6 & 21.093 & 1 & .000 \\
\hline
\end{tabular}

$\mathrm{P} \leq 0.05$ 